Putra, et al/Jurnal Ekonomi Syariah Teori dan Terapan Vol. 6 No. 5 Mei 2019: 993-1006; ZAKAT PRODUKTIF DALAM MENINGKATKAN KUALITAS PENDIDIKAN MUSTAHIQ DITINJAU DARI STANDAR PENILAIAN PENDIDIKAN, STANDAR PROSES, DAN STANDAR SARANA PRASANA (STUDI KASUS LAZ INISIATIF ZAKAT INDONESIA CABANG JAWA TIMUR)

\title{
ZAKAT PRODUKTIF DALAM MENINGKATKAN KUALITAS PENDIDIKAN MUSTAHIQ DITINJAU DARI STANDAR PENILAIAN PENDIDIKAN, STANDAR PROSES, DAN STANDAR SARANA PRASANA (STUDI KASUS LAZ INISIATIF ZAKAT INDONESIA CABANG JAWA TIMUR)'
}

\author{
Dimas Rizky Syah Putra \\ Departemen Ekonomi Syariah-Fakultas Ekonomi dan Bisnis-Universitas Airlangga \\ Email: dimas.rizky.syah-2014@feb.unair.ac.id \\ Tika Widiastuti \\ Departemen Ekonomi Syariah-Fakultas Ekonomi dan Bisnis-Universitas Airlangga \\ Email: tika.widiastuti@feb.unair.ac.id
}

\begin{abstract}
:
Zakat productive is the utilization of zakat through productive management and empowerment processes, which in practice is carried out by channeling capital into mustahiq which is then managed to fulfill their welfare in the future. This research aims to analyze the role of productive zakat managed by LAZ IZI which has a role in improving the quality of mustahiq education in the Surabaya City. The results of this research indicate that productive zakat funds managed by LAZ IZI play a role in educational assessment standards in the form of increasing GPA for students and report cards for students, then in standard processes in the form of increases in study hours, training and activeness of intra and extra organizations, and the role in standard facilities and infrastructures in the form of increasing learning needs equipment such as notebooks, textbooks, stationery, and other facilities.

Keywords : Productive Zakat, Mustahiq, Education Quality.
\end{abstract}

\section{PENDAHULUAN}

Tingkat pertumbuhan ekonomi dan kesejahteraan masyarakat seringkali dijadikan sebagai tolak ukur sebuah negara agar bisa dikatakan sebagai negara yang berkembang atau bahkan negara maju. Dari berbagai macam permasalahan yang ada di Indonesia maka ketimpangan dan kesenjangan merupakan sebuah dilema yang dieluelukan masyarakat. Ketidak merataan distribusi pendapatan dan kekayaan menyebabkan problematika bagi pemerintahan yang harus segera diselesaikan. Kemiskinan yang tidak diperhatikan dan tidak segera diselesaikan akan menimbulkan berbagai
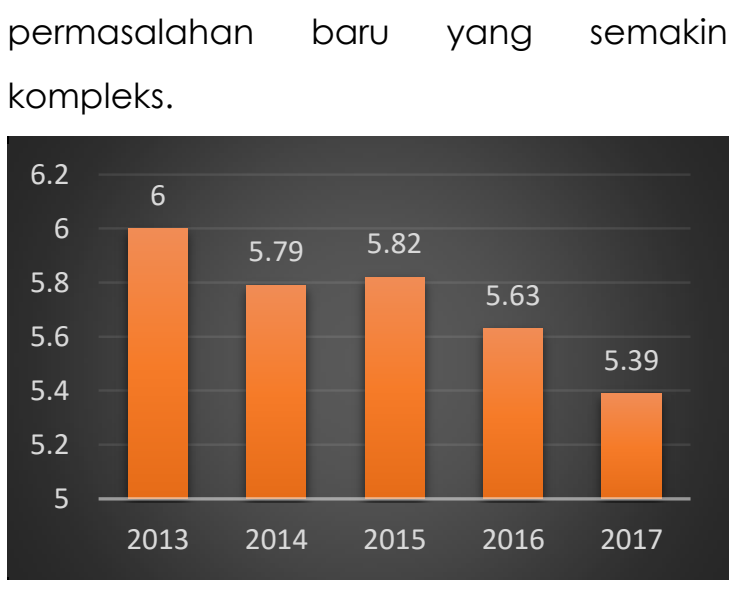

Sumber : BPS, Diolah Peneliti

\section{Gambar 1.}

Persentase Tingkat Kemiskinan di Kota Surabaya Tahun 2013-2017

Melihat dari Gambar 1.1 dapat disimpulkan bahwa pada Kota Surabaya juga mengalami penurunan dari tahun

\footnotetext{
${ }^{1}$ Jurnal ini merupakan bagian dari skripsi Dimas Rizky Syah Putra, NIM: 04141 1431074, yang diuji pada tanggal 23 Januari 2019.
} 
Putra, et al/Jurnal Ekonomi Syariah Teori dan Terapan Vol. 6 No. 5 Mei 2019: 993-1006; ZAKAT PRODUKTIF DALAM MENINGKATKAN KUALITAS PENDIDIKAN MUSTAHIQ DITINJAU DARI STANDAR PENILAIAN PENDIDIKAN, STANDAR PROSES, DAN STANDAR SARANA PRASANA (STUDI KASUS LAZ INISIATIF ZAKAT INDONESIA CABANG JAWA TIMUR)

ketahun. Dari Gambar 1.1 kita dapat melihat bahwa persentase tingkat kemiskinan di Kota Surabaya mengalami penurunan yang sangat signifikan pada 5 tahun terakhir. Pada tahun 2017 tingkat kemiskinan berada pada angka 5,39\%. Selain dari tingkat kemiskinan, kita juga dapat melihat dari garis ketimpangan atau gini ratio pada Kota Surabaya yang juga mengalami penurunan. Akan tetapi gini ratio pada Kota Surabaya tidak mengalami penurunan yang cukup signifikan dari tahun ke tahun. Hal ini berarti bahwa garis ketimpangan dan kesenjangan yang terjadi sangat tinggi.

Banyak program, cara, serta kebijakan yang diluncurkan oleh pemerintah guna mengatasi permasalahan ketimpangan dan kesenjangan yang akan semakin memperparah kemiskinan di Indonesia. Pertumbuhan ekonomi yang tidak terdistribusi secara merata akan berdampak negatif pada berbagai sektor khususnya sektor pendidikan. Akan tetapi banyak dari program serta kebijakan pemerintah yang bersifat umum tersebut terbukti masih belum bisa menyelesaikan permasalahan pendidikan di Indonesia yang sangat kompleks. Maka dari itu di dalam ajaran agama Islam juga terdapat instrumen yang mampu dan berpotensi untuk menyelesaikan berbagai persoalan dan problema yang ada di Indonesia khususnya pada sektor pendidikan. Instrumen tersebut adalah zakat.
Zakat adalah instrumen dalam Islam yang mampu meminimalisir bahkan menghapus ketimpangan dan kesenjangan akibat dari ketidak merataan distribusi pendapatan dan kekayaan pada masyarakat. Menurut kamus ensiklopedia bebas bahasa Indonesia, zakat dalam segi istilah adalah harta tertentu yang wajib dikelvarkan oleh orang yang beragama Islam dan diberikan kepada golongan yang berhak menerimanya atau yang biasa kita sebut sebagai 8 asnaf.

Ditinjau dari segi bahasa zakat mempunyai arti bersih,suci,subur, berkat, dan berkembang. Menurut ketentuan yang telah ditetapkan oleh syariat Islam zakat merupakan rukun ketiga dari rukun Islam. Menurut Yusuf Qardhawi (2007), arti pertumbuhan dalam arti bahwa penerbitan zakat sebagai alasan untuk pertumbuhan dan pengembangan aset, pelaksanaan zakat menyebabkan pahala meningkat. Sementara makna suci menunjukkan bahwa zakat memurnikan jiwa dari keburukan, kebohongan dan pemurnian dari dosa. Dan jika seseorang memiliki karakter zaka dalam arti yang baik, maka orang itu memiliki karakter yang lebih baik. Seseorang yang berarti zaki adalah orang yang memiliki banyak karakteristik orang baik.

Menurut Tika \& Imron (2016:374), pada tahun 2001 Departemen Agama RI membentuk Direktorat Pengembangan Zakat dan Wakaf melalui Keputusan Menteri Agama RI no. 1/2001 untuk 
Putra, et al/Jurnal Ekonomi Syariah Teori dan Terapan Vol. 6 No. 5 Mei 2019: 993-1006; ZAKAT PRODUKTIF DALAM MENINGKATKAN KUALITAS PENDIDIKAN MUSTAHIQ DITINJAU DARI STANDAR PENILAIAN PENDIDIKAN, STANDAR PROSES, DAN STANDAR SARANA PRASANA (STUDI KASUS LAZ INISIATIF ZAKAT INDONESIA CABANG JAWA TIMUR)

memperkuat institusi zakat dan mengoptimalkan pengelolaan zakat. Peraturan ini menjelaskan mengenai ketentuan pengelolaan dan pengumpulan zakat, pembinaan lembaga pengelola zakat. Berdasarkan data penelitian Badan Amil Zakat Nasional (BAZNAS) pada tahun 2016 potensi zakat di Indonesia mencapai angka Rp 286T, akan tetapi realisasi pengumpulannya hanya 3,7 trilyun dengan jumlah pendistribusian sebesar 2,2 trilyun dapat diartikan tingkat realisasi zakat hanyalah 1\% dari jumlah potensi dari zakat itu sendiri. Oleh karena itu setiap Lembaga Amil Zakat (LAZ) dituntut untuk mengelola dan mendayagunakan dana zakat dengan semaksimal mungkin.

Berdasarkan data dari penelitian Badan Amil Zakat Nasional (BAZNAS) pada tahun 2017, zakat mengalami tren yang semakin meningkat pada setiap tahunnya, hal ini berarti bahwa kinerja OPZ juga mengalami peningkatan. Di Indonesia Organisasi Pengelola Zakat (OPZ) terdiri dari Badan Amil Zakat Nasional (BAZNAS), BAZNAS Provinsi, BAZNAS Kabupaten/Kota, dan Lembaga Amil Zakat (LAZ).

Organisasi Pengelola Zakat (OPZ) mengumpulkan dan mengelola dana yang berasal dari zakat, infaq, sedekah, wakaf dan dana sosial lainnya. Akan tetapi sumber dana yang terbesar diperoleh dari zakat. Pada tahun 2017 sumber dana zakat sebesar $67,38 \%$ atau sebesar 4,19 triliun rupiah dari total pengumpulan OPZ sebesar 6,2 triliun rupiah. Sebagai perbandingan pada tahun 2016 sumber dana zakat sebesar $74,51 \%$ atau sebesar 3,74 triliun rupiah dari total pengumpulan OPZ sebesar 5,02 triliun rupiah.

Di Kota Surabaya sendiri banyak LAZ yang sudah menerapkan programprogram pengelolaan dana zakat dalam bidang pendidikan. Dana zakat yang berhasil dikumpulkan dan dikelola oleh LAZ akan didistribusikan kepada mustahiq dalam bentuk bantuan beasiswa untuk siswa maupun mahasiswa yang ada di Surabaya. Hal ini terbukti jika zakat tidak hanya sebatas pada fungsi konsumtif, melainkan juga memiliki fungsi produktif.

Zakat produktif adalah pendayagunaan zakat secara produktif yang pemahamannya lebih kepada bagaimana cara atau metode menyampaikan dana zakat kepada sasaran dalam pengertian yang lebih luas, sesuai dengan ruh dan tujuan syara'(Herwindo \& Nisful, 2014:663). Zakat produktif dalam jangka panjang diharapkan dapat memberdayakan masyarakat yang awalnya adalah mustahiq sehingga bisa menjadi muzakki.

Zakat produktif yang dikelola oleh LAZ sangat berperan terhadap peningkatan kualitas pendidikan di Kota Surabaya. Keberadaan LAZ di Surabaya diharapkan mampu membantu pemerintah dalam menyelesaikan permasalahan pendidikan yang ada di Surabaya. Dalam ajaran agama Islam 
Putra, et al/Jurnal Ekonomi Syariah Teori dan Terapan Vol. 6 No. 5 Mei 2019: 993-1006; ZAKAT PRODUKTIF DALAM MENINGKATKAN KUALITAS PENDIDIKAN MUSTAHIQ DITINJAU DARI STANDAR PENILAIAN PENDIDIKAN, STANDAR PROSES, DAN STANDAR SARANA PRASANA (STUDI KASUS LAZ INISIATIF ZAKAT INDONESIA CABANG JAWA TIMUR)

pendidikan menjadi prioritas karena dengan pendidikan maka manusia bisa menjaga fitrahnya.

Yayasan Inisiatif Zakat Indonesia IZI - dilahirkan oleh sebuah lembaga sosial yang sebelumnya telah dikenal cukup luas dan memiliki reputasi yang baik selama lebih dari 16 tahun dalam memelopori era baru gerakan filantropi Islam modern di Indonesia yaitu Yayasan Pos Keadilan Peduli Ummat (PKPU).

Berdasarkan latar belakang yang telah diuraikan di atas, maka rumusan masalah dari proposal ini adalah, "Bagaimana peran zakat produktif dalam meningkatkan kualitas pendidikan mustahiq ditinjau dari standar penilaian pendidikan, standar proses, dan standar sarana prasarana?".

Adapun tujuan penelitian yang akan diperoleh dari penelitian ini adalah untuk mengetahui bagaimana peran zakat produktif dalam meningkatkan kualitas pendidikan mustahiq ditinjau dari standar penilaian pendidikan, standar proses, dan standar sarana prasarana.

\section{LANDASAN TEORI}

Zakat secara istilah mempunyai arti sejumlah harta tertentu yang diwajibkan oleh Allah SWT kepada orangorang yang sudah memenuhi syariat dan ketentuan untuk berzakat (muzakki) dan diserahkan kepada orang-orang yang berhak mendapatkan zakat (mustahiq) disamping untuk mengeluarkan jumlah harta tertentu tersebut. Arti tumbuh dan suci itu sendiri tidak hanya digunakan sebagai tools untuk mensucikan harta kekayaan, akan tetapi lebih daripad itu zakat juga mempunyai manfaat dalam ranah spiritual. Zakat juga berfungsi untuk mensucikan jiwa orang yang mengeluarkan zakat dan menumbuhkan kebaikan-kebaikan di dalamnya (Ryandono, 2008:2).

Golongan orang yang berhak menerima zakat dalam Islam disebut juga mustahiq. zakat yang sudah dihimpun dan dikelola wajib untuk didistribusikan kepada para mustahiq. Didalam Al-Qur'an surat At-Taubah ayat 60 disebutkan bahwa mustahiq terdiri dari 8 golongan atau yang biasa disebut 8 asnaf, yaitu fakir, miskin, amil, mualaf, riqab, gharim, fii sabilillah, dan ibnu sabil.

Menurut Asnaini (2008) zakat produktif adalah zakat yang melalui proses pengelolaan dan pemberdayaan secara produktif, yang dalam prakteknya dilakukan dengan cara menyalurkan modal kepada para mustahiq yang kemudian dikelola untuk memenuhi kesejahteraan hidup mereka untuk masa yang akan datang. Zakat produktif adalah pendayagunaan zakat secara produktif yang pemahamannya lebih kepada bagaimana cara atau metode menyampaikan dana zakat kepada sasaran dalam pengertian yang lebih luas, sesuai dengan ruh dan tujuan syara'(Herwindo \& Nisful, 2014:663). Zakat produktif dalam jangka panjang diharapkan dapat memberdayakan 
Putra, et al/Jurnal Ekonomi Syariah Teori dan Terapan Vol. 6 No. 5 Mei 2019: 993-1006; ZAKAT PRODUKTIF DALAM MENINGKATKAN KUALITAS PENDIDIKAN MUSTAHIQ DITINJAU DARI STANDAR PENILAIAN PENDIDIKAN, STANDAR PROSES, DAN STANDAR SARANA PRASANA (STUDI KASUS LAZ INISIATIF ZAKAT INDONESIA CABANG JAWA TIMUR)

masyarakat yang awalnya adalah mustahiq sehingga bisa menjadi muzakki.

Menurut Sartika (2008:77), pengembangan zakat bersifat produktif akan lebih optimal bila dilaksanakan Badan Amil Zakat atau Lembaga Amil Zakat karena sebagai organisasi yang terpercaya untuk pengalokasian, pendayagunaan, dan pendistribusian. Berbicara masalah penghimpunan, pengelolaan, dan pendistribusian zakat di Indonesia, peran pemerintah saat ini sudah digantikan oleh Badan Amil Zakat (BAZ) atau Lembaga Amil Zakat (LAZ). Di Indonesia sendiri sudah banyak berdiri BAZ dan LAZ yang tersebar di berbagai daerah. Dalam prakteknya, BAZ atau LAZ dalam memberikan zakat produktif, harus juga melakukan pembinaan dan pendampingan kepada mustahiq. Dalam konteks zakat produktif yang diberikan pada bidang pendidikan, maka harus dilakukan pembinaan dan pendampingan intelektual dan rohani pada mustahiq. Serta BAZ dan LAZ harus memantau perkembangan dari mustahiq tersebut untuk penilaian dan evaluasi.

Zakat memiliki manfaat dalam jangka pendek maupun jangka panjang tergantung pada cara pengelolaanya. Apabila pengelolaannya hanya memungut kemudian memberikan langsung kepada mustahiq, maka zakat tersebut hanya akan memberi manfaat dalam jangka pendek atau bersifat sementara, tetapi zakat diberikan dalam bentuk modal usaha akan memberi manfaat dalam jangka panjang (Ryandono, 2008:55).

Dalam konteks penelitian ini, modal usaha yang dimaksudkan adalah pemberian dana bantuan pendidikan atau beasiswa kepada mustahiq. Dari penjelasan tentang zakat produktif diatas dapat disimpulkan bahwa zakat produktif adalah dana zakat yang diperuntukan untuk kegiatan produktif sehingga memberikan dampak jangka panjang dan berkesinambungan bagi mustahiq dan tidak hanya untuk sekali konsumsi saja. Salah satu bentuk penyaluran dana zakat produktif dapat dilakukan dengan cara memberikan dana bantuan pendidikan atau beasiswa kepada mustahiq, memberikan pelatihan dan pendampingan dalam kegiatan mustahiq, kemudian memberikan evaluasi dan penilaian.

Menurut M. Quraish Shihab (1999:280), kualitas merupakan indikator dari baik buruknya sesuatu atau tingkat dari mutu sesuatu. Secara bahasa kualitas bisa diartikan dengan meningkatnya suatu hal menuju kearah perbaikan dan atau kemapanan. Karena menurut Kamus Besar Bahasa Indonesia, kualitas adalah merupakan tingkat atau kadar dari baik dan buruknya sesuatu. Jika melihat pengertian diatas maka kita bisa menyimpulkan bahwa kualitas pendidikan adalah tingkat keberhasilan pendidikan yang dicapai oleh seseorang atau lembaga melalui beberapa indikator 
Putra, et al/Jurnal Ekonomi Syariah Teori dan Terapan Vol. 6 No. 5 Mei 2019: 993-1006; ZAKAT PRODUKTIF DALAM MENINGKATKAN KUALITAS PENDIDIKAN MUSTAHIQ DITINJAU DARI STANDAR PENILAIAN PENDIDIKAN, STANDAR PROSES, DAN STANDAR SARANA PRASANA (STUDI KASUS LAZ INISIATIF ZAKAT INDONESIA CABANG JAWA TIMUR)

dengan tujuan mencetak generasi yang lebih baik di masa depan.

Menurut Peraturan Pemerintah Republik Indonesia Nomor 32 tahun 2013 tentang Perubahan atas Peraturan Pemerintah (PP) No. 19 Tahun 2005 tentang Standar Nasional Pendidikan ada 8 hal yang harus diperhatikan untuk mewujudkan pendidikan yang berkualitas.Akan tetapi pada realisasinya peneliti hanya menggunakan tiga dari delapan standar pendidikan dalam mengukur peningkatan kualitas pendidikan mustahiq. Ketiga standar itu adalah standar penilaian pendidikan, standar sarana dan prasarana, serta standar proses. Lima standar yang lain berhubungan langsung dengan sekolah atau perguruan tinggi mustahiq sehingga tidak dapat diukur. Peran zakat produktif dalam meningkatkan kualitas pendidikan mustahiq dapat diliat dari beberapa kriteria penilaian seperti peningkatan ratarata nilai rapor pada siswa atau peningkatan IPK pada mahasiswa, pemenuhan peralatan belajar, dan peningkatan waktu belajar serta keaktifan dalam berorganisasi atau ekstrakurikuler. Kriteria tersebut dapat dinilai pada waktu mustahiq sebelum menerima beasiswa yang berasal dari dana zakat produktif dan setelah mustahiq menerima beasiswa tersebut.

\section{METODE PENELITIAN}

Pendekatan yang akan digunakan dalam penelitian ini adalah pendekatan penelitian kualitatif. Menurut Yin (2009:2) pendekatan kualitatif adalah pendekatan dengan menggunakan data yang berupa kalimat tertulis atau lisan, persitiwaperistiwa, pengetahuan atau proyek studi yang bersifat deskriptif. Penelitian ini berawal dari pencarian data berupa perspektif narasumber dalam bentuk cerita secara detail dan atau cerita asli mereka, kemudian peneliti bersama para narasumber akan memberi penafsiran sehingga menciptakan konsep sebagai temuan.

Menurut Sugiyono (2015:1), metode penelitian kualitatif adalah penelitian yang bermaksud untuk memahami fenomena tentang apa yang dialami oleh objek penelitian secara alamiah, dan peneliti merupakan key instrumen.Menurut Yin (2009:7) terdapat lima strategi dalam penelitian kualitatif yaitu (1) eksperimen, (2) survei, (3) analisis arsip, (4) historis, dan (5) studi kasus. Strategi yang digunakan dalam penelitian ini adalah strategi penelitian studi kasus. Peneliti menggunakan strategi penelitian studi kasus karena yang pertama, menurut Yin studi kasus merupakan strategi yang cocok digunakan apabila pokok pertanyaan penelitian berkenaan dengan How dan atau Why. Kedua, peneliti hanya memiliki sedikit kontrol atau bahkan tidak sama sekali terhaap objek penelitian. Ketiga, fokus penelitian terletak pada fenomena-fenomena kontemporer yang terjadi di dalam konteks kehidupan nyata. Sumber dan jenis data dalam penelitian diperoleh dengan cara sebagai berikut: 
Putra, et al/Jurnal Ekonomi Syariah Teori dan Terapan Vol. 6 No. 5 Mei 2019: 993-1006; ZAKAT PRODUKTIF DALAM MENINGKATKAN KUALITAS PENDIDIKAN MUSTAHIQ DITINJAU DARI STANDAR PENILAIAN PENDIDIKAN, STANDAR PROSES, DAN STANDAR SARANA PRASANA (STUDI KASUS LAZ INISIATIF ZAKAT INDONESIA CABANG JAWA TIMUR)

\section{Data primer}

Dalam penelitian ini data primer berasal dari key informan (informan kunci) yaitu pengelola LAZ yang memahami program pengelolaan dan pendistribusian dari dana zakat produktif untuk bidang pendidikan melalui program beasiswa. Dari objek penelitian ini diharapkan mendapatkan informasi mengenai bagaimana program yang dilakukan oleh LAZ IZI dalam mengelola dan mendistribusikan dana zakat produktif.

Informan lainnya adalah para mustahiq yang merupakan peserta penerima beasiswa yang mendapat pembinaan dan pelatihan program dari LAZ IZI. Dari objek penelitian ini diharapkan mendapatkan informasi dari pengeloaan dan pendistribusian dana zakat produktif untuk bidang pendidikan yang sesuai dengan syariat Islam.

\section{Data sekunder}

Dalam penelitian ini data sekunder berasal dari dokumen-dokumen informasi yang diperoleh dari LAZ IZI mengenai data-data penerima beasiswa pendidikan. selain itu peneliti dapat memperoleh data melalui rekaman dan dokumentasi pribadi. Peneliti juga dapat memperoleh informasi melalui buku-buku terkait zakat, jurnal, internet, makalah, dan literatur atau kajian pustaka yang relevan atau berkaitan dengan permasalahan.

Penelitian ini menggunakan teknik triangulasi sumber yang dilakukan dengan cara mengkroscek data yang telah didapat melalui berbagai sumber. Selain itu triangulasi sumber juga dilakukan dengan cara membandingkan dan mengecek baik derajat kepercayaan suatu informasi yang diperoleh melalui waktu ke waktu dan alat yang berbeda. Dalam penelitian ini teknik triangulasi data sumber dilakukan untuk menguji validitas data tentang peran zakat produktif. Maka pengumpulan dan pengujian data yang telah diperoleh dapat dilakukan kepada mustahiq yang menjadi peserta penerima dana zakat produktif dalam bentuk beasiswa pendidikan, selain itu dapat pula dilakukan dengan membandingkan hasil wawancara dengan dokumen yang berkaitan.

Dalam penelitian ini peneliti menggunakan teknik analisis pembuatan penjelasan (naratif-deskriptif) atau dengan cara pembuatan penjelasan yang dilakukan melalui metode analisis data dan mendeskripsikan hasil dari wawancara yang bertujuan untuk mengetahui secara mendalam mengenai peran zakat produktif terhadap peningkatan kualitas pendidikan di Kota Surabaya dengan menggunakan studi kasus LAZ IZI. Analisis penelitian yang dilakukan adalah dengan cara membandingkan penemuan atau bukti-bukti dengan proposisi yang dibuat oleh peneliti. Kemudian proses yang akan dikerjakan adalah menganalisis data penelitian secara umum. Menurut Yin (2009:133), tahap analisis data terdiri dari pengujian, pengkategorian, pentabulasian dan 
Putra, et al/Jurnal Ekonomi Syariah Teori dan Terapan Vol. 6 No. 5 Mei 2019: 993-1006; ZAKAT PRODUKTIF DALAM MENINGKATKAN KUALITAS PENDIDIKAN MUSTAHIQ DITINJAU DARI STANDAR PENILAIAN PENDIDIKAN, STANDAR PROSES, DAN STANDAR SARANA PRASANA (STUDI KASUS LAZ INISIATIF ZAKAT INDONESIA CABANG JAWA TIMUR)

pengkombinasian data. Dengan demikian akan muncul proses-proses kejadian dari kasus yang diteliti dan ditemukan makna data yang sesuai dengan tujuan penelitian.

\section{ANALISIS DAN PEMBAHASAN}

\section{Analisis Hasil Wawancara}

Hasil penelitian yang diperoleh peneliti adalah berdasarkan kepada penelitian langsung yang dilakukan oleh peneliti di lapangan. Selama proses wawancara dengan informan internal maupun eksternal, peneliti mendapatkan berbagai macam informasi mengenai apakah zakat produktif yang dikelola dan disalurkan oleh LAZ IZI cabang Jawa Timur dalam bentuk program-program beasiswa pendidikan berpengaruh terhadap peningkatan kualitas pendidikan di Kota Surabaya, kemudian apa saja programprogram pendidikan yang dilakukan oleh LAZ IZI cabang Jawa Timur. Selain itu peneliti juga mendapatkan informasi mengenai manfaat dari beasiswa pendidikan yang dirasakan langsung oleh mustahiq apakah dapat meningkatkan kualitas pendidikan yang ditinjau dari 3 standar yaitu standar proses, standar sarana dan prasana, dan standar penilaian pendidikan.

\section{Penyaluran Zakat Produktif LAZ IZI Bidang} Pendidikan

Setelah peneliti melakukan wawancara kepada informan yang sudah ditentukan dan melakukan survey ke tempat penelitian, peneliti mendapatkan informasi dan data mengenai penyaluran dana zakat dari LAZ Inisiatif Zakat Indonesia. LAZ IZI menyalurkan dana zakat yang sudah dihimpun melalui berbagai macam program yang sudah dibuat. Berikut dibawah ini merupakan table penyaluran dana zakat oleh LAZ IZI kepada mustahiq sesuai dengan bidang dan program.

Melihat pada Tabel 4.1 bahwa pada tahun 2017 zakat produktif yang disalurkan LAZ IZI pada bidang pendidikan sebesar Rp 806.770.709. Jika melihat dari besar total penyaluran kepada empat bidang yaitu bidang kesehatan, bidang pendidikan, bidang ekonomi dan bidang dakwah yang berjumlah Rp 2.498.357.048 maka penyaluran pada bidang pendidikan menempati urutan kedua dimana penyaluran zakat produktif terbesar yaitu pada bidang kesehatan.

Tabel 1.

\section{Penyaluran Pada Program Berdasarkan} Jumlah Nominal 2017

\begin{tabular}{|c|l|r|l|}
\hline NO & PROGRAM & $\begin{array}{r}\text { JUMLAH } \\
\text { PENYALURAN } \\
\text { (Rp) }\end{array}$ & persentase \\
\hline 1 & Kesehatan & Rp 1,132,559,459 & $45.3 \%$ \\
\hline 2 & Pendidikan & Rp 806,770,709 & $32.4 \%$ \\
\hline 3 & Ekonomi & Rp 320,103,880 & $12.8 \%$ \\
\hline 4 & Dakwah & Rp 238,923,000 & $9.5 \%$ \\
\hline & Total & Rp, 2,498,357,048 & $100 \%$ \\
\hline Sumbr & & \multicolumn{2}{|c|}{} \\
\hline
\end{tabular}

Sumber : Hasil Wawancara 5 Desember 2018, Diolah Peneliti.

LAZ IZI terbukti telah menyalurkan dana zakat produktifnya dengan masif pada bidang pendidikan. Hal tersebut 
Putra, et al/Jurnal Ekonomi Syariah Teori dan Terapan Vol. 6 No. 5 Mei 2019: 993-1006; ZAKAT PRODUKTIF DALAM MENINGKATKAN KUALITAS PENDIDIKAN MUSTAHIQ DITINJAU DARI STANDAR PENILAIAN PENDIDIKAN, STANDAR PROSES, DAN STANDAR SARANA PRASANA (STUDI KASUS LAZ INISIATIF ZAKAT INDONESIA CABANG JAWA TIMUR)

dapat dilihat dari keseluruhan penyaluran dalam bentuk persentase dengan bidang pendidikan sebesar $32,4 \%$.

\section{Peran Zakat Produktif Dalam Standar}

Penilaian Pendidikan

Standar penilaian pendidikan adalah standar yang berkaitan dengan mekanisme, prosedur, dan instrumen penilaian hasil belajar peserta didik. Standar penilaian pendidikan meliputi peningkatan nilai IPK pada mahasiswa dan rata-rata nilai rapor pada siswa sebelum dan sesudah mendapat bantuan pendidikan. Dibawah ini merupakan tabel data hasil wawancara dengan informan terkait.

Tabel 2.

Standar Penilaian Pendidikan

\begin{tabular}{|c|c|c|c|c|}
\hline No & Informan & $\begin{array}{l}\text { Program } \\
\text { Beasiswa }\end{array}$ & $\begin{array}{l}\text { Sebelum } \\
\text { Mendap } \\
\text { at } \\
\text { Beasiswa }\end{array}$ & $\begin{array}{l}\text { Setelah } \\
\text { Mendapat } \\
\text { Beasiswa }\end{array}$ \\
\hline 1 & $\begin{array}{l}\text { Informan } \\
\text { keempat }\end{array}$ & $\begin{array}{l}\text { Rumah } \\
\text { Inisiatif }\end{array}$ & IPK 2.98 & IPK 3.28 \\
\hline 2 & $\begin{array}{l}\text { Informan } \\
\text { kelima }\end{array}$ & $\begin{array}{l}\text { Rumah } \\
\text { Inisiatif }\end{array}$ & IPK 3.06 & IPK 3.19 \\
\hline 3 & $\begin{array}{l}\text { Informan } \\
\text { keenam }\end{array}$ & Charity & $\begin{array}{l}\text { Nilai } \\
\text { rapor } \\
\text { rata-rata } \\
76\end{array}$ & $\begin{array}{l}\text { Nilai rapor } \\
\text { rata-rata } \\
79.25\end{array}$ \\
\hline \multirow[t]{2}{*}{4} & \multirow[t]{2}{*}{$\begin{array}{l}\text { Informan } \\
\text { ketujuh }\end{array}$} & \multirow[t]{2}{*}{ Charity } & $\begin{array}{l}\text { Nilai } \\
\text { rapor } \\
\text { rata-rata } \\
\text { Hanif } \\
82.25\end{array}$ & $\begin{array}{l}\text { Nilai rapor } \\
\text { rata-rata } \\
\text { Hanif } 85.5\end{array}$ \\
\hline & & & $\begin{array}{l}\text { Nilai } \\
\text { rapor } \\
\text { rata-rata } \\
\text { Shafa } 84\end{array}$ & $\begin{array}{l}\text { Nilai rapor } \\
\text { rata-rata } \\
\text { Shafa } 87\end{array}$ \\
\hline
\end{tabular}

Sumber : Hasil Wawancara Dengan Mustahiq Tanggal 12,13,14 Desember 2018, Diolah Peneliti.

Dari hasil wawancara yang peneliti lakukan kepada empat orang informan yang merupakan tiga orang mustahiq dan satu orangtua mustahiq yang sudah menerima beasiswa pendidikan dari LAZ IZI cabang Jawa Timur, peneliti menyimpulkan bahwa zakat produktif yang dikelola oleh IZI dan disalurkan kepada mustahiq berupa beasiswa pendidikan berperan dalam meningkakan kualitas pendidikan mustahiq melalui standar penilaian pendidikan.

Pada informan keempat mengalami peningkatan nilai IPK sebesar 0,3 setelah mendapatkan beasiswa, sedangkan pada informan kelima mengalami peningkatan nilai IPK sebesar 0,13 . Pengukuran peningkatan nilai IPK pada informan keempat dan informan kelima dilakukan pada periode awal setelah mendapatkan beasiswa. Pada informan keenam mengalami peningkatan pada rata-rata nilai rapor sebesar 3,25, sedangkan pada informan ketujuh mengalami peningkatan pada anak pertamanya sebesar 3,25 dan pada anak keduanya sebesar 3. Pengukuran peningkatan rata-rata nilai rapor pada informan keenam dan ketujuh dilakukan pada periode awal setelah mendapatkan beasiswa dan menggunakan empat mata pelajaran yaitu Bahasa Indonesia, Bahasa Inggris, Matematika, dan Pendidikan Agama Islam. 
Putra, et al/Jurnal Ekonomi Syariah Teori dan Terapan Vol. 6 No. 5 Mei 2019: 993-1006; ZAKAT PRODUKTIF DALAM MENINGKATKAN KUALITAS PENDIDIKAN MUSTAHIQ DITINJAU DARI STANDAR PENILAIAN PENDIDIKAN, STANDAR PROSES, DAN STANDAR SARANA PRASANA (STUDI KASUS LAZ INISIATIF ZAKAT INDONESIA CABANG JAWA TIMUR)

Peran Zakat Produktif Dalam Standar Proses

Standar Proses adalah standar nasional pendidikan yang berkaitan dengan pelaksanaan pembelajaran pada satu satuan pendidikan untuk mencapai standar kompetensi lulusan. Standar proses meliputi peningkatan proses belajar dan keaktifan mustahia pada kegiatan ekstra seperti organisasi, les, atau bimbingan belajar lainnya sebelum mendapatkan beasiswa dan setelah mendapatkan beasiswa.

Dari hasil wawancara yang peneliti lakukan kepada empat orang informan yang merupakan tiga orang mustahia dan satu orangtua mustahiq yang sudah menerima beasiswa pendidikan dari LAZ IZI cabang Jawa Timur, peneliti menyimpulkan bahwa zakat produktif yang dikelola oleh $\mid \mathrm{ZI}$ dan disalurkan kepada mustahiq berupa beasiswa pendidikan berperan dalam meningkakan kualitas pendidikan mustahiq melalui standar proses pendidikan meliputi peningkatan proses belajar dan keaktifan mustahiq pada kegiatan organisasi intra dan ekstra kampus, serta berbagai latihan.

informan keempat mengalami peningkatan jam belajar sebanyak dua jam, informan kelima mengalami peningkatan jam belajar sebanyak dua jam, informan keenam mengalami peningkatan jam belajar sebanyak satu setengah jam, dan pada informan ketujuh, kedua anaknya mengalami peningkatan jam belajar sebanyak satu jam. Kemudian informan keempat dan kelima mengalami peningkatan pada keaktifan organisasi dimana kedua informan mengikuti organisasi ekstra kampus yang sebelumnya hanya mengikuti organisasi intra kampus, sedangkan pada informan keenam dan kedua anak dari informan ketujuh tidak mengikuti organisasi pada sebelum dan sesudah mendapatkan beasiswa. Pada informan keempat dan kelima mengalami peningkatan pada pelatihan yang didapat pada program beasiswa Rumah inisiatif, pada informan keenam tidak mengikuti pelatihan sebelum dan sesudah mendapatkan beasiswa, dan pada kedua anak dari informan ketujuh mengalami peningkatan pelatihan ngaji tahfidzdimana sebelumnya tidak mengikuti pelatihan sama sekali.

\section{Peran Zakat Produktif Dalam Standar Sarana Prasarana}

Standar sarana dan prasarana adalah standar nasional pendidikan yang berkiatan dengan kriteria minimal tentang ruang belajar, tempat berolah-raga, tempat beribadah, perpustakaan, laboratorium, bengkel kerja, tempat bermain, tempat berkreasi serta sumber belajar lain, yang diperlukan untuk menunjang proses pembelajaran, termasuk penggunaan teknologi dan informasi. Dalam penelitian ini menggunakan tolak ukur peralatan belajar dan fasilitas belajar seperti buku tulis, binder, alat tulis, dan fasilitas lainnya 
Putra, et al/Jurnal Ekonomi Syariah Teori dan Terapan Vol. 6 No. 5 Mei 2019: 993-1006; ZAKAT PRODUKTIF DALAM MENINGKATKAN KUALITAS PENDIDIKAN MUSTAHIQ DITINJAU DARI STANDAR PENILAIAN PENDIDIKAN, STANDAR PROSES, DAN STANDAR SARANA PRASANA (STUDI KASUS LAZ INISIATIF ZAKAT INDONESIA CABANG JAWA TIMUR)

yang menunjang proses pembelajaran mustahiq.

Mustahiq yang menajadi informan pada penelitian ini merupakan mustahiq dalam asnaf fakir, miskin, dan fii sabilillah, dalam artian mereka yang mendapat beasiswa adalah dari golongan yang tidak mampu dan membutuhkan bantuan berupa beasiswa. Sebelum mustahiq mendapat beasiswa dari IZI, mustahiq merasa sulit dan tidak mampu untuk memenuhi kebutuhan peralatan belajar. Oleh karena itu salah satu fungsi zakat adalah mempersempit jurang ketimpangan dengan cara mendistribusikan penghasilan dan kekayaan secara merata.

Dari hasil wawancara yang peneliti lakukan kepada empat orang informan yang merupakan tiga orang mustahia dan satu orangtua mustahiq yang sudah menerima beasiswa pendidikan dari LAZ IZI cabang Jawa Timur, peneliti menyimpulkan bahwa zakat produktif yang dikelola oleh IZI dan disalurkan kepada mustahiq berupa beasiswa pendidikan berperan dalam meningkakan kualitas pendidikan mustahiq melalui standar sarana dan prasarana yang meliputi peningkatan peralatan belajar serta kebutuhan lainnya yang mendukung kegiatan belajar. Selain itu mustahia juga mendapatkan fasilitas lainnya berupa asrama tempat tinggal, wifi, dan printer.

Informan keempat menjelaskan bahwa selain mendapatkan vang 600.000 rupiah/bulan, program Rumah Inisiatif juga memberikan fasilitas lain dalam bentuk asrama tempat tinggal, wifi dan printer. Dalam memenuhi kebutuhan peralatan belajarnya, mustahiq dalam program Rumah Inisiatif dapat menggunakan vang bulanan tersebut untuk membeli peralatan perkuliahan sesuai dengan kebutuhannya.Informan kelima juga membenarkan pernyataan dari informan keempat bahwa program Rumah Inisiatif memberikan vang bulanan dan fasilitas tempat tinggal, wifi, dan printer bagi mustahiq yang menerima beasiswa.Pernyataan dari kedua informan diatas yang merupakan mustahiq penerima beasiswa Rumah Inisiatif juga diperkuat oleh pernyataan key informan. Beliau menyampaikan bahwa IZI sudah menyediakan fasilitas berupa tempat tinggal gratis dan juga vang bulanan. Akan tetapi dalam alokasinya itu kembali pada mustahiq sesuai dengan kebutuhan mereka.

Selanjutnya informan keenam menjelaskan bahwa ada setelah mendapatkan beasiswa dari IZI yang berupa vang sekolah dan vang ijazah, kebutuhan belajarnya lainnya menjadi terpenuhi. Hal ini karena sebelum mendapat beasiswa dari IZI, informan keenam masih harus melunasi uang bulanan sekolahnya. Tetapi setelah mendapat beasiswa dari IZI beliau tidak merasa terbebani uang sekolah lagi dan bisa mengalokasikan untuk membeli peralatan belajar.Begitu juga dengan informan ketujuh yang merupakan 
Putra, et al/Jurnal Ekonomi Syariah Teori dan Terapan Vol. 6 No. 5 Mei 2019: 993-1006; ZAKAT PRODUKTIF DALAM MENINGKATKAN KUALITAS PENDIDIKAN MUSTAHIQ DITINJAU DARI STANDAR PENILAIAN PENDIDIKAN, STANDAR PROSES, DAN STANDAR SARANA PRASANA (STUDI KASUS LAZ INISIATIF ZAKAT INDONESIA CABANG JAWA TIMUR)

orangtua dari kedua mustahiq yang mendapatkan beasiswa dari IZI. Beliau menjelaskan bahwa tanggungan beliau sebagai orangtua sedikit dimudahkan setelah anaknya mendapatkan beasiswa.

\section{SIMPULAN}

\section{Kesimpulan}

Berdasarkan hasil penelitian dan analisis pembahasan yang dilakukan oleh peneliti, maka kesimpulan yang dapat diambil adalah sebagai berikut:

1. Dana zakat produktif yang dikelola oleh LAZ IZI cabang Jawa Timur yang kemudian disalurkan kepada mustahiq dalam bentuk beasiswa pendidikan berperan dalam meningkatkan kualitas pendidikan mustahiq di Kota Surabaya melalui tiga standar yaitu standar penilaian pendidikan, standar proses dan standar sarana dan prasarana

2. Zakat produktif dalam bentuk beasiswa pendidikan berperan dalam peningkatan kualitas pendidikan mustahiq dalam standar penilaian pendidikan. Setelah mendapatkan beasiswa, dua mustahiq yang merupakan mahasiswa Perguruan Tinggi Negeri mengalami peningkatan IPK. Sedangkan pada tiga mustahiq lainnya yang merupakan pelajar mengalami peningkatan pada ratarata nilai rapor mereka.

3. Zakat produktif dalam bentuk beasiswa pendidikan berperan dalam peningkatan kualitas pendidikan mustahiq dalam standar proses. Setelah mendapatkan beasiswa, mustahiq mengalami peningkatan dalam jam belajar karena beberapa faktor diantaranya program asrama yang menerapkan jam kondusif belajar dan timbulnya rasa syukur pada mustahiq yang kemudian mendorong semangat untuk lebih giat belajar. Kemudian pada mustahiq mahasiswa mengalami peningkatan pada keakifan organisasi baik di dalam maupun di luar kampus. Sedangkan pada mustahiq pelajar mengalami peningkatan yaitu mengikuti pelatihan tahfidz setelah mendapatkan beasiswa.

4. Zakat produktif dalam bentuk beasiswa pendidikan berperan dalam peningkatan kualitas pendidikan mustahiq dalam standar sarana dan prasarana. Setelah mendapatkan beasiswa, kebutuhan peralatan belajar mustahiq menjadi terpenuhi seperti kebutuhan buku tulis, alat tulis, buku belajar untuk UNAS, kalkulator, dan flashdisk. Sedangkan pada mustahia program Rumah Inisiatif mendapatkan fasilitas lain berupa asrama tempat tinggal, wifi gratis, printer gratis, makan gratis dan vang bulanan.

5. Bentuk program-program pendidikan, pembinaan, dan pelatihan yang diberikan oleh LAZ IZI cabang Jawa Timur kepada mustahiq penerima beasiswa adalah pelatihan tahfidz (hafalan qur'an), tahsin(bacaan qur'an), sirah nabawiyah (kajian mengenai akhlak nabi), pelatihan 
Putra, et al/Jurnal Ekonomi Syariah Teori dan Terapan Vol. 6 No. 5 Mei 2019: 993-1006; ZAKAT PRODUKTIF DALAM MENINGKATKAN KUALITAS PENDIDIKAN MUSTAHIQ DITINJAU DARI STANDAR PENILAIAN PENDIDIKAN, STANDAR PROSES, DAN STANDAR SARANA PRASANA (STUDI KASUS LAZ INISIATIF ZAKAT INDONESIA CABANG JAWA TIMUR)

bahasa Inggris, pelatihan kepemimpinan, dan pelatihan kewirausahaan.

Saran

Berdasarkan dari hasil dan pembahasan penelitian serta wawancara dengan informan, maka timbul beberapa saran bagi beberapa pihak, yaitu :

1. Bagi Lembaga Amil Zakat Inisiatif Zakat Indonesia cabang Jawa Timur agar kedepannya bisa lebih optimal dalam menyalurkan dana zakat pada bidang pendidikan dan bisa menyentuh target dan sasaran mustahiq dari tingkat siswa Sekolah Dasar hingga mahasiswa Perguruan Tinggi.

2. Bagi Lembaga Amil Zakat Inisiatif Zakat Indonesia cabang Jawa Timur agar bisa lebih mengembangkan programprogram beasiswa pendidikan yang tidak hanya berfokus pada ilmu agama, akan tetapi juga program lainnya seperti pelatihan softskills, kepemimpinan, dan kewirausahaan yang sangat bermanfaat bagi mustahiq kedepannya.

3. Bagi Pemerintah dan atau dinas terkait agar bisa lebih memperhatikan dan membantu mengembangkan lembaga-lembaga amil zakat seperti |z| dalam bentuk regulasi, finansial, maupun sosialiasi kepada masyarakat tentang potensi zakat yang sangat besar. Karena dengan keberadaan dan berkembangnya lembagalembaga zakat atau yayasan seperti IzI dapat membantu meningkatkan kualitas pendidikan di daerah sekitarnya.

4. Bagi penelitian selanjutnya, diharapkan dapat meneliti secara komperhensif mengenai potensi zakat yang dikelola oleh LAZ agar kedepannya bisa lebih maksimal dalam hal pengumpulan dan pengelolaan zakat pada aspek produktif.

5. Peraturan Pemerintah Republik Indonesia Nomor 32 tahun 2013 tentang Perubahan atas Peraturan Pemerintah (PP) No. 19 Tahun 2005 tentang Standar Nasional Pendidikan.

6. Qardhawi, Yusuf. 2007. Hukum Zakat. Terjemahan. Jakarta: Pustaka Litera Antar Nusa.

\section{DAFTAR PUSTAKA}

Adinugroho, Achmad Setio, Nuraini, Dwi dan Riyanto, Dwi. 2018. Statistik Zakat Nasional 2017. Badan Amil Zakat Nasional.

Asnaini. 2008. Zakat Produktif Dalam Perspektif Hukum Islam. Yogyakarta: Pustaka Pelajar.

https://izi.or.id/

https://kbbi.web.id/didik

https://www.bps.go.id/

Nidityo, Herwindo Ghora \& Laila, Nisful. 2014. Zakat Produktif Untuk Meningkatkan Kinerja Produksi, Motivasi Dan Religiusitas Mustahiq. Surabaya.

Ryandono, Muhammad Nafik Hadi. 2008. Ekonomiziswaq(Zakat, Infaq, 
Shadaqah, dan Waqaf). Surabaya:

IFDI dan Cenforis.

Sartika, Mila. 2008. Pengaruh

Pendayagunaan Zakat Produktif

Terhadap Pemberdayaan

Mustahiq Pada Laz Yayasan Solo

Peduli Surakarta. vol.ii no. 1, juni 2008.

Shihab, Muhammad Quraish.1999.

Membumikan Al-Quran. Bandung :

Mizan.

Sugiyono. 2015. Memahami Penelitian Kualitatif. Bandung: Alfabeta.

Widiastuti, Tika. Mawardi, Imron. 2016.

Optimalisasi Pengelolaan Dana Zakat di Lembaga Zakat daerah : Pendekatan SWOT (strength, weakness, opportunity, threat) Analysys. Surabaya. Politeknik Negeri Banjarmasin.

Yin, Robert. K. 2009. Studi Kasus; Desain dan Metode. Jakarta. Raja Grafindo Persada.

Zaenal, Muhammad Hasbi. 2017. Indonesia Zakat Outlook 2018. Badan Amil Zakat Nasional. 